Esta revista forma parte del acervo de la Biblioteca Jurídica Virtual del Instituto de Investigaciones Jurídicas de la UNAM http://www.juridicas.unam.mx https://biblio.juridicas.unam.mx https://revistas.juridicas.unam.mx DOI: http://dx.doi.org/10.22201/iij.24484881e.2021.44.16171

COMENTARIOS LEGISLATIVOS 
Esta revista forma parte del acervo de la Biblioteca Jurídica Virtual del Instituto de Investigaciones Jurídicas de la UNAM

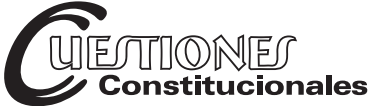

Revista Mexicana de Derecho Constitucional

Núm. 44, Enero-Junio 2021

ISSN (versión electrónica): 2448-4881

\section{Breve reconstrucción histórica del surgimiento de la Hacienda Pública en la Constitución del Estado de México*}

\author{
Brief historical reconstruction of the emergence of the Treasury \\ in the Constitution of the State of Mexico
}

\author{
Sonia Elizabeth RAMOS-MEDINA**
}

RESUMEN: El objetivo propuesto se centra en trazar una breve reconstrucción histórica del surgimiento y estado actual de la Hacienda Pública desde la primera Constitución del Estado de México. El análisis confirma la mutabilidad de la HP cuya tradicional separación funcional ha ido paulatinamente sustituyéndose hasta extinguirse. Se identifican momentos clave en la evolución de los estudios jurídicos en la materia hasta llegar finalmente a la supresión de los apartados de la Constitución dedicados a estos fines.

Palabras clave: Hacienda Pública; Constitución Estatal; Reformas.
ABSTRACT: The proposed objective focuses on tracing a brief historical reconstruction of the emergence and current state of the Public Treasury since the first Constitution of the State of Mexico. The analysis confirms the mutability of the HP whose traditional functional separation has been gradually replaced until its extinction. Key moments are identified in the evolution of legal studies on the subject until finally reaching the suppression of the sections of the Constitution dedicated to these purposes.

Keywords: Public Finance; State Constitution; Reforms.

* Constitución Política del Estado Libre y Soberano de México. Última reforma mediante decreto número 153 de la "LX" Legislatura, publicada en el Periódico oficial "Gaceta del Gobierno" el 24 de junio de 2020. [Online] https://bit.ly/2G6QycY Consultado el 25 de agosto 2020.

** Doctora en Estudios Fiscales por la Universidad Autónoma de Sinaloa (UAS), México. Becaria posdoctoral en España por el Consejo Nacional de Ciencia y Tecnología (Conacyt). México. Correo electrónico: elizabeth.ramos@usal.es. ORCID: 0000-00030760-327X. 
Esta revista forma parte del acervo de la Biblioteca Jurídica Virtual del Instituto de Investigaciones Jurídicas de la UNAM

\section{CONSIDERACIONES GENERALES}

En el examen de la actividad financiera realizada por entidades públicas territoriales e institucionales, es importante considerar la composición de la Hacienda Pública (HP), así como los procedimientos a través de los cuáles se desarrolla, puesto que la riqueza del país en sus distintas formas está subordinada al interés general. Tradicionalmente la HP ha sido concebida como territorial, bajo una óptica unitaria que no plantea escenarios a distintos niveles (Oates, 1977: xi). Sobre la articulación de la HP debemos tener en cuenta que el contenido de este fenómeno es por esencia heterogéneo, y por tanto la naturaleza de los elementos que la integran tendrán distintos criterios y principios de ordenación. La Hacienda Pública llama a dos disciplinas - tributaria y presupuestaria - a proporcionar las bases para enfrentar la realidad financiera en la que, la armónica conjunción de principios rectores conformará el desarrollo de la actividad financiera (Vicente-Arche Domingo, 1974: 535).

Esta reflexión se centra en la Constitución del Estado de México específicamente en aquel sector del ordenamiento jurídico que regula la constitución y gestión de la HP. Desde un punto de vista estático, ${ }^{1}$ nos preguntamos sobre su concepción, los elementos que la integran, su titularidad, obligaciones del Estado, entre otras.

Esto resulta interesante al considerar que, en el ordenamiento jurídico mexicano, a fin de garantizar la armonización a nivel nacional, las leyes generales contemplan la distribución de competencias y las formas de coordinación entre la Federación, las entidades federativas y los municipios conforme las bases que dispone la Constitución Política de los Estados Unidos Mexicanos (CPEUM). ${ }^{2}$ Por un lado, es claro que la CPEUM se apoya en leyes secundarias, sin embargo, tanto esta última como la Ley

1 Estas consideraciones se dirigirán principalmente a lo estático, quedando para otros estudios el análisis desde el punto de vista dinámico sobre la gestión de la HP, es decir, "el conjunto de procedimientos mediante los que derechos y obligaciones de contenido económico se convierten, respectivamente, en ingresos y gastos”. Martín Queralt, J. et al. (2014: 34).

2 Constitución Política de los Estados Unidos Mexicanos. Diario Oficial de la Federación. Tomo V, Cuarta Época, Núm. 30, de 5 de febrero de 1917. Última reforma del 8 de mayo de 2020. Título quinto, "De los estados de la Federación y de la Ciudad de México", artículo 115. Disponible en: https://bit.ly/2DabZZy. Consultado el 25 de agosto 2020.

Cuestiones Constitucionales, Núm. 44, Enero-Junio 2021

ISSN: $2448-4881$ 
Esta revista forma parte del acervo de la Biblioteca Jurídica Virtual del Instituto de Investigaciones Jurídicas de la UNAM

Federal de Presupuesto y Responsabilidad Hacendaria (LFPRH), ${ }^{3}$ utilizan locuciones generales para referirse a la Hacienda Pública, aunque ninguna lo define de manera explícita.

Por ejemplo, la Constitución Española ${ }^{4}$ no acuña la definición de HP, sin embargo, la Ley General Presupuestaria ${ }^{5}$ advierte desde la exposición de motivos que "el Capítulo II se ocupa del régimen jurídico de la Hacienda Pública estatal en cuanto titular de derechos y obligaciones de contenido económico, partiendo del concepto de Hacienda Pública contemplado en la Ley de 4 de enero de 1977, y ratificado por el texto refundido aprobado por Real Decreto Legislativo 1091/1999, de 23 de septiembre". Por tanto, la sección primera, "Derechos de la Hacienda Pública" estatal del mencionado capítulo, comienza en el artículo 5.1-2 definiéndola como "el conjunto de derechos y obligaciones de contenido económico cuya titularidad corresponde a la Administración General del Estado y a sus organismos autónomos". Además, señala que sus derechos se clasifican en: de naturaleza pública y de naturaleza privada, y especifica que los de naturaleza pública incluyen los tributos y los demás derechos de contenido económico que deriven del ejercicio de potestades administrativas.

Por otro lado, las Constituciones Estatales en México están subordinadas a la CPEUM, los poderes de los Estados se organizarán según lo establecido en el artículo 116; además, no podrán "en ningún caso contravenir las estipulaciones del Pacto Federal” (artículo 41); adoptando para su régimen interior la forma de gobierno republicano, representativo, democrático, laico y popular, teniendo como base de su división territorial y de su organización política y administrativa, el municipio libre..." (artículo 115). Y aunque existe una fuerte vinculación de las Constituciones estatales con la regulación federal, en aquellas cuestiones

3 Congreso de la Unión. (2006). Ley Federal de Presupuesto y Responsabilidad Hacendaria. México, Diario Oficial de la Federación del 30 de marzo 2006. Última reforma publicada el 19 de noviembre de 2019. Disponible en: https://bit.ly/2QzG082. Consultado el 25 de agosto 2020.

4 Véase Constitución Española. Boletín Oficial del Estado. Núm. 311, de 29 de diciembre de 1978, pp. 29313 a 29424. Última modificación de 27 de septiembre de 2011. Disponible en: https://bit.ly/3jpYCDM. Consultado el 25 de agosto 2020.

5 España. Ley 47/2003, de 26 de noviembre, General Presupuestaria. Boletín Oficial del Estado. Núm. 284 de 27 de noviembre de 2003. Última actualización publicada el 5 de agosto de 2020 . 
Esta revista forma parte del acervo de la Biblioteca Jurídica Virtual del Instituto de Investigaciones Jurídicas de la UNAM

no previstas por la CPEUM los estados podrán establecer su organización de manera individual. Es decir, las entidades federativas con una estructura político-territorial plural y compleja tendrán que proyectar su actividad sobre el espacio que les pertenece, pues cada uno de ellos dispone de su propia Hacienda Pública. Por lo que la concepción de esta tomará una forma particular en cada una de las 32 Constituciones políticas de las entidades federativas.

\section{BREVE RECONSTRUCCIÓN HISTÓRICA DEL SURGIMIENTO DE LA HaCienda PÚblica EN la CONSTITUCiÓN Política DEL ESTAdo Libre y SOBERANO DE MÉXICO}

A efectos de este apartado interesa trazar de manera sucinta, a partir de la primera Constitución del Estado de México, el surgimiento de los preceptos dedicados a la Hacienda Pública.

La aprobación y publicación del Acta Constitutiva de la Federación Mexicana mediante Decreto del Congreso Constituyente del 31 de enero de 1824, trajo como efecto natural que en los años siguientes se fueran instaurando las Constituciones propias de las Entidades Federativas.

Entre los esfuerzos previos a la primera Constitución del Estado de México podemos citar el Decreto sobre la Organización Provisional del Gobierno Interior del Estado de México (Téllez y Piña, 2001: 5-6) presentado ante el Congreso Constituyente en marzo de 1824. Desde entonces, se consideraba dentro de las Comisiones designadas, entre otras, la de HP.

Como consecuencia de las declaraciones planteadas en este Decreto se promulgó la "Ley Orgánica Provisional para arreglo del Estado Libre Independiente y Soberano de México" ". En su Capítulo II Poder Legislativo, art 9, manifestaba como una competencia del Congreso: "(IV) fijar los gastos del estado y establecer para cubrirlos las contribuciones que juzgue necesarias"; y, "(V) examinar y aprobar las cuentas de inversión de los caudales del estado". El Capítulo XI dedicado a la Hacienda, no solo establecería una Tesorería General del Estado para la entrada de todos los caudales recaudados (artículo 68), sino que además establecería la contaduría y glosa de las cuentas del estado (artículo 69) y una Institución que articulara las oficinas que servían a estos fines.

\footnotetext{
6 Sancionada por el Congreso Constituyente el 6 de agosto de 1824.
}

Cuestiones Constitucionales, Núm. 44, Enero-Junio 2021

ISSN: $2448-4881$ 
Esta revista forma parte del acervo de la Biblioteca Jurídica Virtual del Instituto de Investigaciones Jurídicas de la UNAM

El penúltimo Estado de la Federación en aprobar su Constitución fue el Estado de México el 14 de febrero de 1827 (González Oropeza, 2017: 432) con un total de 237 artículos distribuidos en nueve títulos. En el quinto se introducen algunas innovaciones respecto a la Hacienda Pública del Estado. Se dividen en tres capítulos: I) De la Hacienda Pública; II) Tesorería General del Estado, y III) Contaduría General del Estado. El primer capítulo señala los elementos que conforman la HP "se formará de las contribuciones que el congreso decretáre y de los demás bienes que le pertenezcan" (artículo 218), así como el período para decretarlas "todos los años en las sesiones de marzo" (artículo 219), prohíbe decretar contribuciones que no sean las precisas para cubrir el presupuesto (artículo 220). El capítulo II manifiesta que será en la tesorería general donde "entrarán real o virtualmente todos los caudales del estado" (artículo 223), y que el tesorero no podrá efectuar pagos que no estén estipulados en las leyes y reglamentos (fijos y periódicos), así como los extraordinarios - acordados y convenidos- (artículo 224). Por último, el capítulo III señala que en la Contaduría General "se glosarán todas las cuentas de los caudales públicos en todos sus ramos" (artículo 226) y su intervención se realizará con arreglo a las leyes de ingresos y egresos de caudales de la tesorería (artículo 227).

El 15 de octubre de 1861 se promulga la segunda Constitución del Estado de México, incluyó en XXXV capítulos, 200 artículos más cuatro transitorios. Aunque se trataba de un nuevo texto sus raíces de hondo raigambre en la antigua Constitución del Estado, reprodujeron, "en su mayor parte, las sabias y bien calculadas disposiciones" de aquélla. Esta actualización se encaminó para establecer una profunda modificación con concordancia con "el progreso de la sociedad [retocando lo que] tenía ya de anticuado y de superfluo", según se afirma en la exposición de motivos, la idea era "ponerla en armonía con los respetables preceptos de la Constitución Federal de 1857 y leyes de reforma" (Robles Martínez, 2001: 144145). Los capítulos XXIX, XXX y XXXI fueron dedicados a: la Hacienda, la Tesorería y la Contaduría respectivamente. La única modificación en el Capítulo de HP establecía que "el Estado es dueño de todos los bienes muebles o inmuebles que estén vacantes en su territorio, y de todos los que dejaren los que mueran intestados sin herederos" (artículo 172).

No obstante, en los años venideros México tendría, de manera paralela, dos gobiernos enfrentados entre sí: el régimen republicano libe- 
Esta revista forma parte del acervo de la Biblioteca Jurídica Virtual del Instituto de Investigaciones Jurídicas de la UNAM

ral y una monarquía - que se planteaba como constitucional-. Ambos gobiernos expidieron diversas disposiciones legislativas, sin embargo, la República liberal no consideró legítima una parte importante de las leyes expedidas por la monarquía (Vázquez Laslop, 2016: 220). En este sentido, el contexto sugiere que, en este periodo y como resultado de las inquietudes de la clase política, los cambios son una constante que encuentra verificación en un texto constitucional reformado en diversas ocasiones. $^{7}$

Estas modificaciones conducirían a la tercera Constitución del Estado, promulgada el 1.o de diciembre de 1870: Ocho títulos subdivididos en secciones y a su vez en capítulos, con un total de 127 artículos más uno transitorio. El título tercero contenía dos secciones: I) De la Hacienda Pública (artículos 103 y 104); II) De la Contaduría de glosa y de la tesorería general (artículos 105-108). Se trata en definitiva de una reducción importante no solo del número de preceptos sino del contenido dispuesto para estas materias.

\section{LA ESPECIALIZACIÓN DE LA HACIENDA PÚBLICA EN EL ORDENAMIENTO JURÍDICO DE 1917}

El 8 de noviembre de 1917 se promulgó la cuarta Constitución del Estado de México. Un texto organizado, esta vez, en libros divididos en títulos con capítulos y secciones, 235 artículos y ocho transitorios. El libro IV denominado "Prevenciones generales a que deberá sujetarse la administración pública" fraccionado en cinco títulos, destinó el título segundo a la organización de la HP. En la figura 1 se representa la estructura del título segundo de este libro. Se trata de una especialización de la organización de la HP. En primer lugar, aunque habíamos planteado un fuerte vínculo entre la Constitución Federal y las Estatales, este ordenamiento considera pertinente e importante que queden establecidos los principios en los que se inspirará el régimen de la HP. Incluso al realizar un análisis comparativo de los textos originales de las Constituciones Estatales a partir de la CPEUM de 1917, podemos corroborar que, ninguna de ellas incluye tantas subsecciones en materia de HP.

7 Reformas de: 3 y 4 de mayo; 2 y 6 de octubre de 1869, y 24 de marzo de 1870. Véase Reyes Pastrana (2015: 144-145).

Cuestiones Constitucionales, Núm. 44, Enero-Junio 2021

ISSN: $2448-4881$ 
Esta revista forma parte del acervo de la Biblioteca Jurídica Virtual del Instituto de Investigaciones Jurídicas de la UNAM

Figura 1

ESTRUCTURA DEL TÍTULO II DEL LIBRO IV

DE LA CONSTITUCiÓN DEL EsTAdo DE MÉXICO DE 1917

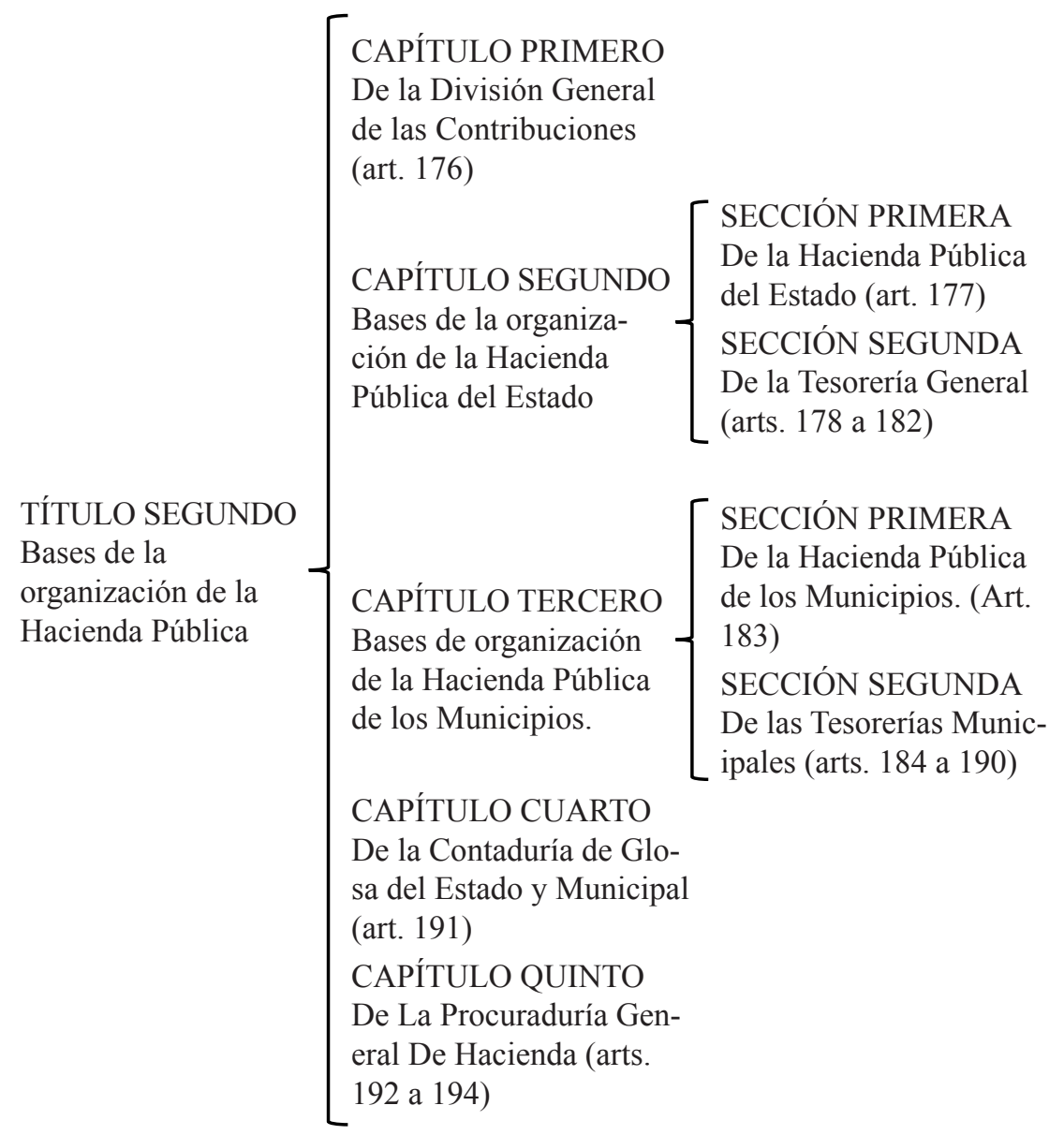

Fuente: Elaboración propia a partir de la Constitución del Estado de México de 1917.

\section{REFORMA DE 1995 Y ACTUALIDAD}

Mas tarde, la Constitución de 1917 exterioriza una serie de imperfecciones, así como adecuaciones respecto a la Constitución federal, que sugie- 
Esta revista forma parte del acervo de la Biblioteca Jurídica Virtual del Instituto de Investigaciones Jurídicas de la UNAM

ren la necesidad de correcciones que acumularon medio millar de modificaciones. Por lo que tuvo lugar una reestructuración Constitucional total con el decreto de $1995,{ }^{8}$ que tendría principalmente como objetivo, la articulación en partes homogéneas del ordenamiento (adicionando o derogando libros, títulos, capítulos, secciones, artículos) (González Oropeza, 2017: 449). La reforma trajo consigo una simplificación de la estructura original y al mismo tiempo una disminución de los artículos que integran la Constitución: 235 artículos, renumerados y reducidos a 150. En lo que aquí interesa, hemos de subrayar una modificación importante en Hacienda Pública: la exposición de motivos advierte que el artículo 177 atinente a la composición de la Hacienda Pública del Estado se reubica y pasa a ser materia competencial de la Legislatura.

Actualmente la Constitución del Estado de México se estructura en títulos, capítulos y secciones, un total de 149 artículos más 15 transitorios. La última reforma que se registró fue publicada en el periódico oficial Gaceta del Gobierno el 24 de junio de 2020. En este texto se pueden observar algunas incógnitas que dejan en la penumbra a la Hacienda Pública tanto la puesta en marcha como su funcionamiento, y que no logran explicarse teniendo como referente una de la Constituciones más especializadas en esta materia.

El Estado podría establecer desde el ámbito de competencias de la HP los principios y reglas básicas sobre aspectos organizativos y funcionales, y considerar dentro de esta materia su composición y estructura. Sin embargo, el ordenamiento ha reservado en exclusiva dentro de las facultades y obligaciones del Gobernador del Estado, "cuidar la recaudación y buena administración de la Hacienda Pública del Estado".

Esto representa a nuestro juicio un retroceso. Incluso aquellos esfuerzos previos a la primera Constitución, aunque reconocían como una competencia del Congreso la fijación de gastos del estado y el establecimiento de contribuciones (actividades propias de la Hacienda Pública), la "Ley Orgánica Provisional”, como hemos mencionado, dedicaba un capítulo a esta materia, donde se vislumbraba ya la importancia de una institución articuladora.

8 Reforma publicada en la Gaceta del Gobierno el 27 de febrero de 1995.

9 Constitución Política del Estado Libre y Soberano de México, Título Cuarto Del Poder Público del Estado, Capítulo Tercero Del Poder Ejecutivo, Sección Segunda De las Facultades y Obligaciones del Gobernador del Estado, artículo 77, fracción XXI.

Cuestiones Constitucionales, Núm. 44, Enero-Junio 2021

ISSN: $2448-4881$ 
Esta revista forma parte del acervo de la Biblioteca Jurídica Virtual del Instituto de Investigaciones Jurídicas de la UNAM

Algunas de las incógnitas que deberían ser despejadas con claridad y precisión en dicho ordenamiento se refieren a la titularidad, los elementos que le conforman, así como los derechos de la HP. En una definición compuesta por 23 Constituciones Estatales ${ }^{10}$, la HP se formará, entre otros, de los bienes y derechos que le pertenezcan, de los ingresos que determine su Ley de Hacienda, De las participaciones, aportaciones, subsidios, transferencias u otros ingresos de origen federal, Ingresos por concepto de convenios, Del producto de las contribuciones o participaciones legales, multas, herencias o reintegros. De estas definiciones se asume la titularidad que corresponde al Estado.

En sentido objetivo, la Hacienda es una expresión eminentemente abstracta, situada dentro de un marco normativo. De esta forma, estas figuras jurídicas preconfiguradas por la norma, al aplicarse, es decir al entrar en contacto con la realidad social y económica, dan nacimiento a derechos y obligaciones (Simón Acosta, 1985: 69). Los "derechos" de la Hacienda Pública podrían entenderse como el repertorio de medios económicos que la Administración Pública emplea para dar cumplimiento a los fines asumidos por esta. Por tanto, podríamos distinguir entre los institutos jurídicos (patrimonio del Estado, deuda pública) como elementos constitutivos de la HP; los derechos de la HP que se generan de la dinámica de los institutos; $\mathrm{y}$, los fondos que como resultado de los ejercicios de los derechos afluyen al Tesoro Público como ingresos (Sainz de Bujanda, 1985: 478). Como ejemplo nos remitiremos una vez más a España, al artículo 20 de la Ley General Presupuestaria ${ }^{11}$ que refuerza el argumento expuesto al manifestar que: "junto a esos derechos nacen obligaciones de las que la Hacienda Pública es responsable, con fuente en la propia ley, de los negocios jurídicos y de los actos o hechos que, según derecho, las generen". Ninguna de las figuras jurídicas anteriores se encuentra consignados textualmente en la actual Constitución del Estado de México.

Por último, el régimen interior de las Entidades Federativas mexicanas tiene "como base de su división territorial y organización política y ad-

10 Además del Estado de México, las Constituciones de los estados de Baja California, Campeche, Jalisco, Michoacán, Oaxaca, Tabasco, Tamaulipas y Yucatán representan las excepciones, sin una definición de Hacienda Pública.

11 España. Ley 47/2003, de 26 de noviembre, General Presupuestaria, título I: "Del ámbito de aplicación y de la Hacienda Pública estatal, capítulo II: "Del régimen de la Hacienda Pública estatal, Sección Cuarta, "Obligaciones de la Hacienda Pública estatal”, artículo 20. 
Esta revista forma parte del acervo de la Biblioteca Jurídica Virtual del Instituto de Investigaciones Jurídicas de la UNAM

ministrativa, el Municipio libre". ${ }^{12}$ Esto es importante en la medida que, en ausencia de un ámbito Estatal, el concepto de Hacienda Pública pueda generalizarse y aplicarse a los municipios del Estado. En este sentido el artículo 125 de la Constitución del Estado de México, cobra relevancia al señalar que serán los municipios quienes administren libremente su Hacienda, ésta última conformada principalmente, por los "rendimientos de los bienes que les pertenezcan, así como de las contribuciones y otros ingresos que la ley establezca", y en todo caso: Contribuciones, participaciones federales e ingresos derivados de la prestación de los servicios públicos a su cargo.

El paso del tiempo ha ido confirmando la mutabilidad de la HP cuya tradicional separación funcional propia de la Hacienda Pública ha ido paulatinamente sustituyéndose hasta extinguirse. De ello queda constancia en este breve análisis histórico, puesto que mientras en la primera Constitución y esfuerzos previos a esta, se celebraba una nueva etapa en la evolución de los estudios jurídicos sobre la Hacienda Pública, al llegar a la Constitución de 1917 quedarían indudablemente asentados, entre otros, los principios de reserva de ley y capacidad económica, avanzando en una especialización en la dogmática jurídico-financiera. Llegados a la reforma de 1995, se diluye la composición de la Hacienda Pública entre las múltiples competencias de la Legislatura que, aunque sus facultades puedan ejercerse en varias de las actuaciones relativas a esta, no justifica la supresión de los apartados de la Constitución dedicados a estos fines.

\section{FUENTES CONSULTADAS}

\section{Constituciones}

Constitución Española. (1978). España: Boletín Oficial del Estado No. 311, pp. 29313 a 29424. Última modificación de 27 de septiembre de 2011. Disponible en: https://bit.ly/3jpYCDM. Consultado el 25 de agosto 2020 .

Constitución Política de los Estados Unidos Mexicanos. (1917). México: Diario Oficial de la Federación Tomo V, Cuarta Época. Núm. 30. Últi-

12 Constitución Política de los Estados Unidos Mexicanos, título quinto: "De los estados de la Federación y de la Ciudad de México", artículo 115.

Cuestiones Constitucionales, Núm. 44, Enero-Junio 2021

ISSN: 2448-4881 
Esta revista forma parte del acervo de la Biblioteca Jurídica Virtual del Instituto de Investigaciones Jurídicas de la UNAM

ma reforma del 08 de mayo de 2020. Título Quinto. De los estados de la Federación y de la Ciudad de México. Artículo 115. Disponible en: https://bit.ly/2DabZZy. Consultado el 25 de agosto 2020.

México. Constitución Política del Estado Libre y Soberano de México. Última reforma mediante decreto número 153 de la "LX" Legislatura, publicada en el Periódico oficial "Gaceta del Gobierno" el 24 de junio de 2020. Disponible en: https://bit.ly/2G6QycY. Consultado el 25 de agosto 2020 .

\section{Legislación}

España. Ley 47/2003, de 26 de noviembre, General Presupuestaria. Boletín Oficial del Estado. Núm. 284 de 27 de noviembre de 2003. Última actualización publicada el 05 de agosto de 2020.

Martín Queralt, J. et al. (2014). Derecho financiero y tributario. 25a. ed. Madrid: Tecnos.

México. Ley Federal de Presupuesto y Responsabilidad Hacendaria. Diario Oficial de la Federación de 30 de marzo 2006. Última reforma publicada el 19 de noviembre de 2019. Disponible en: https://bit. $l y / 2 Q z G 082$. Consultado el 25 de agosto 2020.

\section{Doctrina}

GonzÁlez Oropeza, M. (2017). Digesto Constitucional Mexicano. México: Suprema Corte de Justicia de la Nación.

OATES, W. (1977). Federalismo fiscal, España: Instituto de Estudios de la Administración Local.

Reyes Pastrana, J. (2015). Compendio de Disposiciones Normativas Históricas del Congreso del Estado de México (1824-1914). México: Secretaría de Asuntos Parlamentarios del Poder Legislativo del Estado de México.

Robles Martínez, R. (2001). Historia de las Constituciones del Estado de México. En Andrea SÁnchez, Francisco de (coord.). Derecho constitucional estatal. Estudios históricos, legislativos y teórico-prácticos de los estados de la República mexicana. México: UNAM, Instituto de Investigaciones Jurídicas. 
Esta revista forma parte del acervo de la Biblioteca Jurídica Virtual del Instituto de Investigaciones Jurídicas de la UNAM

Sainz De Bujanda, F. (1985). Sistema de Derecho Financiero, t. I., vol. I., Madrid.

Simón Acosta, E. (1985). El derecho financiero y la ciencia jurídica, Bolonia: Publicaciones del Real Colegio de España.

TÉllez, M. y PIÑA, H. (Comp.). (2001). Colección de Decretos del Congreso del Estado de México, 1824-1910. Tomo I. LVI Legislatura del Estado de México. México: Instituto de Estudios Legislativos y la Universidad Autónoma del Estado de México.

VÁZQUEZ LASLOP, M. (2016). Las leyes del segundo imperio mexicano (1863-1867): Apuntes para el estudio de su textualidad. Cuadernos de la Alfal. Núm. 8.

Vicente-Arche Domingo, F. (1974). Notas sobre gasto público y contribución a su sostenimiento en la Hacienda Pública. Civitas Revista Española de Derecho Financiero. Núm. 3. 